\title{
Nearly 1.3 billion have health insurance in China, but poor still neglected
}

$\mathrm{B}$ y his own admission, Zhang Wei's living situation is far from glamorous. At night he sleeps in a small room in a temporary, two-storey cabin. By day, he's a foreman who oversees the construction of a main road through Dongguan, a bustling city of factories and migrant workers in southern China's Guangdong province.

Although the work is hard and the hours long, his employer does at least cover his health insurance.

Zhang is one of about 1.3 billion citizens - more than $95 \%$ of the population - covered by some form of health insurance, according to government figures. This rate represents substantial progress as the world's most populous nation rapidly rolls out cheap, universal health care, part of reforms started in 2009. It also means that $5 \%$ of the population mostly the poor - still lack coverage.

In $2006,45 \%$ of people were covered, meaning a staggering 600 millionplus have taken up health insurance for the first time in the past seven years. In 2009 , one year ahead of schedule, China attained its goal of offering health insurance to $90 \%$ of the population, according to government data.

"The increase in the past decade is really quite astonishing; I don't know of any other countries that have done that," says Dr. Michael O'Leary, the World Health Organization (WHO) representative in China.

Beijing has focused on three key insurance schemes. First, a mandatory urban-employee policy has premiums from US $\$ 100$ per year and is partly funded by the employer. Second is a voluntary scheme for city residents ineligible for the employee policy - mainly students, the unemployed and seniors that starts at US\$20 per year and is largely funded by the state. And third is the New Rural Cooperative Medical System, the world's largest health insurance scheme with close to 900 million people (up from 410 million in 2006) covered at premiums of US\$20 per year in 2012.

Despite the impressive figures released by Beijing, data suggest that China's health reforms are still failing to reach those in greatest need of health insurance: the poor. Cities such as Shanghai on China's prosperous seaboard have achieved near complete coverage, but less developed areas are lagging.

"Generally speaking, the further west you go, the lower [the insurance coverage in China]," says O'Leary.

The WHO was unable to provide data on insurance coverage for the two largest western provinces: Xinjiang and

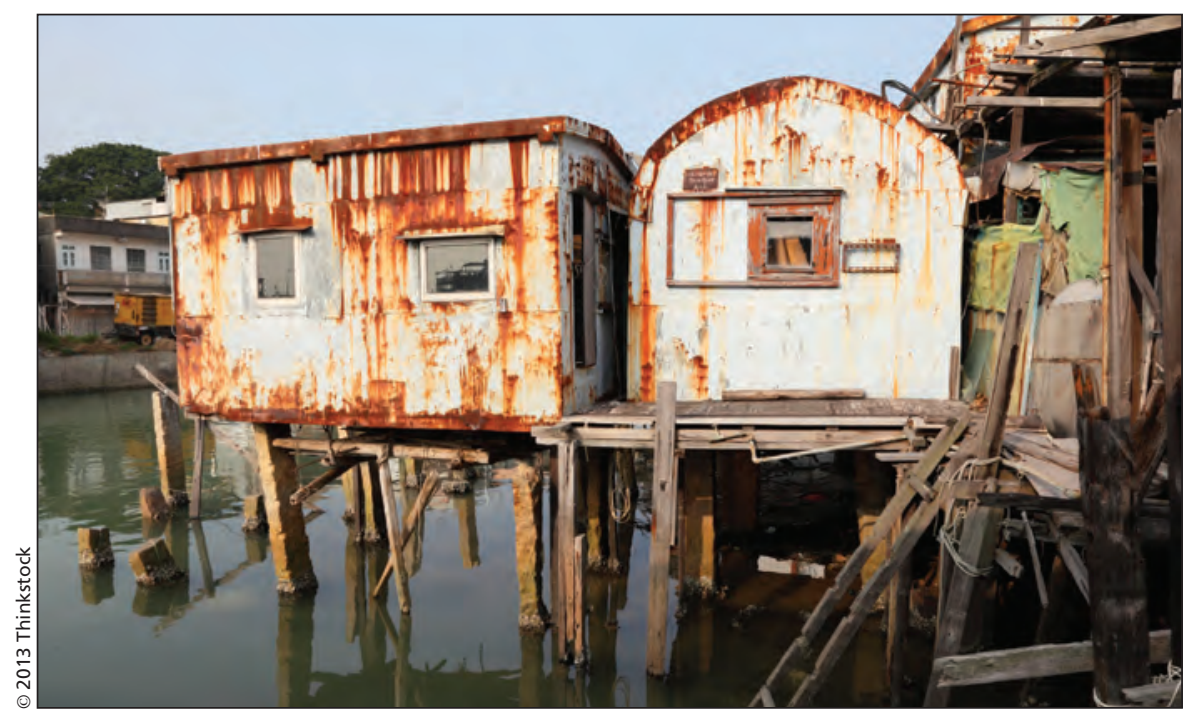

The "hukou" system, China's household registration system typically ties people and their health insurance policies to the places they were born, not to where they actually live and work. This means that millions of migrant workers have no coverage.
Tibet. Dr. Shi Guang, director of the Health Policy Research Division, Ministry of Health, did not respond to emailed questions.

Another key demographic lacking coverage is China's 262 million or so migrant workers.

One of these workers from the central province of Hubei, who gave only his family name, Xie, said that he used to be a teacher, which meant he received insurance. But since switching jobs he is no longer covered.

A key problem is the long-standing "hukou" system. China's household registration system typically ties people and their health insurance policies to the places they were born, and in the cases of millions of migrant workers, not to where they live and work.

According to a comprehensive University of Hong Kong, School of Public Health study published in October, $43.1 \%$ of nonregistered residents were uninsured in Shenzhen, the mainland Chinese city adjacent to Hong Kong.

"Despite visions by the Chinese government to achieve universal health insurance coverage ... as part of its health reform target, migrant workers appear to be neglected from its social health insurance net," concluded study coauthors Kelvin Lam and Janice Johnston.

O'Leary said that Beijing is fully aware of such problems, as well as the thin coverage many policies provide: consultations and medicines are subsidized, but patients still pay a substantial portion of costs, depending on the policy and where they live.

Although China's total health spending more than doubled to an estimated US $\$ 357$ billion between 2006 and 2011, according to global US management consulting firm McKinsey \& Company, public health insurance coverage is still "broad and thin right now," said O'Leary. "So to deepen and improve the quality of coverage - the quality of services provided - those are the very big challenges." - Steve Finch, Shenzhen, China

CMAJ 2013. DOI:10.1503/cmaj.109-4538 